FINAL DOCUMENT FOLLOWING RESPONSES TO REVIEWERS

Cure, S., Hill, A. \& Cruickshank, V. Journal of Outdoor and Environmental Education (2018). https://doi.org/10.1007/s42322-018-0012-y 


\title{
Mistakes, Risk, and Learning in Outdoor Education
}

\author{
Abstract \\ Within many contemporary social, workplace and sporting contexts, mistakes are often \\ perceived to negative, resulting in underperformance and something to be avoided. Within \\ education, in contrast, prominent educational researcher John Hattie (2012) suggests \\ "mistakes are the essence of learning" (p. 26). For Hattie, the role of mistakes within the \\ learning process needs to be seen as positive. Creating opportunities for students to learn \\ from mistakes through effective feedback is key to raising achievement. Yet in traditional \\ outdoor education, where risky activities are often a central feature, the role of mistakes in \\ the teaching and learning process has seldom been examined. This paper, therefore, \\ explores how secondary outdoor education teachers perceive the notion that mistakes are \\ the essence of learning, and how they view the role that mistakes have in the learning \\ processes in their outdoor education programs. Employing a qualitative approach, the \\ findings of this study emphasise teachers' beliefs that mistakes are indeed important in the \\ learning process. The inclusion of mistakes and feedback in outdoor education programs is, \\ however, less than clear. Many teachers spoke of constraints such as short duration \\ programs, not knowing students, and risky activities which made it unlikely for mistakes to \\ be welcomed. In contrast one teacher with a yearlong program sought opportunities for \\ students to make mistakes and learn from these through feedback.
}

\section{Keywords}

Outdoor learning, outdoor education, pedagogy, learning, risk, feedback, mistakes

\section{Running Header}

Mistakes, Risk, and Learning in Outdoor Education 


\section{Introduction}

'You are only as good as your last mistake' is a phrase commonly heard within many corporate and sporting circles. This perspective can place a negative slant on mistakes as something that must be avoided or overcome. Often mistakes in the corporate world will have budgetary, workplace safety or consumer satisfaction implications, and within a sporting context error could mean underperformance. Within education, in contrast, Hattie $(2009,2012)$ suggests "mistakes are the essence of learning" (p. 26). For Hattie, the role of mistakes within the learning process needs to be seen as positive because mistakes, when accompanied with effective feedback, create opportunities for students to learn and improve. Alongside Hattie, there is a strong body of educational literature that delves into the roles that mistakes, feedback, learning environments and formative assessment practices have on student learning. Dweck's (2006) work identifying the importance of a growth mindset grew out of interest in how students respond to failure and how that affects their learning. Related to this, Earl (2013) has focused on the positive ways that good formative assessment and feedback can impact positively on student learning. Yet in adventure orientated versions of outdoor education, where risky activities are often a central feature, the role of mistakes in the teaching and learning process seems to have received less attention in the academic literature. This paper, therefore, explores how secondary outdoor education teachers perceive the notion that mistakes are the essence of learning, and how they view the role that mistakes have in the learning processes in their outdoor education programs.

Within the current Australian National Curriculum the place of outdoor education (OE) is less than clear. As a result, many claims can be made as to the role of OE within schools, including: personal and social development, leadership, group dynamics, acquiring 'hard' adventure skills, and environmental and sustainability education (Hill, 2010; Martin, 2008; Payne \& Wattchow, 2008). In their seminal article, Hattie, Marsh, Neill, and Richards (1997) claimed that "the teachers of outdoor programs have all too rarely used the research from their in-class counterparts to improve their programs and they need to more fully appreciate that they are conducting an educational experience" (pp. 77-78). This suggestion highlights how dominant OE practice has been underpinned by particular sets of activities that are seen to be beneficial for students, rather than by a comprehensive integration of general educational theory and research. Nicol (2002) also points to the dominance of activities in 
$\mathrm{OE}$, suggesting there is a lack of clarity and purpose, as OE has developed "more by chance than design" (p. 90). Much of what has been designed in OE positions risk as a central focus, which in many ways is used to distinguish the outdoor learning environment from its indoor counterparts. In the first decade of the $21^{\text {st }}$ century a number of scholars critically examined the role of risk in $\mathrm{OE}$ through an increased focus on principles of quality teaching and learning (for example see Brookes, 2003a, 2003b; Brown, 2010; Brown \& Fraser, 2009; Zink \& Leberman, 2003). In this paper we seek to further contribute to the debates regarding risk and learning theories in $\mathrm{OE}$ through drawing on the perspectives and reflections of $\mathrm{OE}$ teachers about mistakes and learning.

\section{Aims and significance of the research project}

This paper draws on a small scale research project which investigated the perceptions of Tasmanian OE teachers in relation to quality teaching and learning processes. Specifically, this study sought to understand the pedagogical principles and practices employed by outdoor educators and to examine the role of student mistakes and feedback in outdoor education contexts. The research was guided by the following research questions:

1. How do OE teachers in Tasmania perceive the role of student mistakes accompanied by feedback within outdoor learning processes?

2. How does risk impact on the creation of a learning environment where mistakes are welcomed?

As OE has developed from programs such as Outward Bound into the school curriculum, many principles and philosophies have remained the same. For example, the creation of outcomes relating to an individuals' personal development in characteristics such as resilience, leadership and teamwork is prevalent in OE discourse (Nicol, 2002). Whilst the development of these character traits may be desirable, a modernized "sociocultural lens expands possibilities for how OE is conceptualized, with a focus more on learning" (Brown \& Fraser, 2009, p. 61). In order to shift the focus from development of personal characteristics through high risk activities to one that is more centred on student learning and achievement, outdoor educators have broadened their pedagogical practice by drawing on aspects of teaching and learning theory and research from their classroom counterparts. This shift is a 
particular focus within contemporary OE literature (for example see Hill, 2012; Hill \& Brown, 2014; Wattchow \& Brown, 2011), and is central to this research project.

The creation of a learning environment welcoming of student mistakes and rich with feedback is central to Hattie's $(2009,2012)$ thesis of Visible Learning. How these terms are conceptualised and used in this paper is important to establish. Hattie (2012) employs the terms mistake and error interchangeably and frames error as "the difference between what we know we can do and what we aim to know and do" (p. 115). For Hattie, mistakes can occur where a student has not met the success criteria related to a learning outcome, where knowledge is either incorrect or presented incorrectly, and where skills are demonstrated either incorrectly or insufficiently. The key for Hattie is that mistakes are welcomed in a supportive trusting environment, treated as learning opportunities, and accompanied by feedback.

Hattie uses Sadler's (1989) notion of the 'gap' between where a student is and where they need to be to help conceptualise feedback. Feedback, according to Hattie, helps to reduce that gap by providing students with clear information about where they have gone wrong, and what they need to do to accomplish the task or skill. Earl's (2013) differentiation between evaluative feedback and descriptive feedback is also useful here. Like Hattie, Earl suggests it is important to use descriptive feedback that is task focused, identifying what the mistake was and why it occurred, along with how to improve or move towards a better way of performing or achieving that task. Feedback can come from different sources such as teachers, peers, and through self-evaluation, and can be dependent on the learning context. . It must be noted that feedback from peers can be both positive and damaging, for, as Hattie (2012) suggests, "the greatest reason why students do not like to expose their mistakes is because of their peers: peers can be nasty, brutal and viral" (p. 26).

\section{Mistakes and Traditional Outdoor Education}

The genesis of the modern outdoor and adventure education movement can be traced to Kurt Hahn who, in the midst of World War II, devised the first Outward Bound style programs that aimed to prepare the youth of the time to better handle the hardships they may face within the context of a World War (Hill \& Brown, 2014). The aims of the initial program were to develop independence, initiative, physical fitness, self-reliance and resourcefulness amongst seamen to prevent and reduce the loss of life (Hahn, 1957). As 
Outward Bound programs grew in popularity, these principles remained and participants worldwide were placed in what were perceived to be high-risk situations, often in the wilderness, completing physically and emotionally challenging tasks deliberately aimed at developing personal traits considered by Hahn to be valuable for social wellbeing and enduring hardship (Hattie, Marsh, Neill \& Richards, 1997). These traditional notions have often underpinned contemporary OE practices in Britain (Nicol, 2002), Australia (Payne \& Wattchow, 2008) and Aotearoa New Zealand (Boyes 2012).

Such traditional philosophies in $\mathrm{OE}$, based on high adventure activities, have been critically examined and revised over the last 15 years by a large number of OE scholars. One such critique was presented by Brown (2009), who suggested that outdoor education is in need of more appropriate theoretical foundations related to $21^{\text {st }}$ century learning needs, as opposed to simply preparing youth to endure the hardships of warfare. A further critical comment was provided by Nicol (2002), who argued that the goals of traditional Outward Bound style outdoor education may not be so applicable in contemporary society. Rather, as Lugg (2004) suggested, a stronger focus on educational theory and research as a basis for creating valuable outdoor learning opportunities for students is required.

A key component among the notions of traditional $\mathrm{OE}$ is that success is achieved when students are placed in risky situations and feel outside of their comfort zone. Luckner and Nadler (1997) claimed that "through involvement in experiences that are beyond one's comfort zone, individuals are forced to move into an area that feels uncomfortable and unfamiliar" and then, "by overcoming these anxious feelings, students move to the growth zone" (p. 20). Whilst appropriate levels of challenge are crucial to any successful learning experience (Hattie, 2012), situations that place students in undue stress, or that do not employ appropriate progression or scaffolding, can be counter-productive to learning (for example see Berman \& Davis-Berman, 2005; Brown, 2008; Leberman \& Martin, 2003; Zink \& Leberman, 2003). The creation of a learning environment where students can trust each other and the teacher, where they are feel supported and safe, whilst at the same time challenged, is crucial to positive learning where mistakes are welcomed (Hattie, 2012). The role that risk plays in such a learning environment is important, especially in an OE context.

The constant allure of high-risk activities, as found in traditional OE practices, can lead to programs that bear a closer resemblance to amusement parks than educational endeavours (Beames \& Brown, 2016). Whilst students might have an enjoyable and exciting 
experience in a tightly controlled activity, Brown and Fraser (2009) suggest there is "little in the way of growth and learning opportunities in artificial situations that in effect do not require significant decision-making by the learner, and thus no ownership of consequences" (p. 70). These points are particularly salient to this study. As the role of risk acting as a central pillar to the learning experience is critically examined, alternative principles of teaching and learning should be found within an experience to amplify the learning process without creating catastrophic consequences.

\section{Mistakes and Educational Research}

The interplay of mistakes with feedback is a central concern within broader educational theory and research. As Hattie (2012) suggests, the "optimal classroom climate for learning is one that generates an atmosphere of trust - a climate in which it is understood that is okay to make mistakes, because mistakes are the essence of learning" (p. 26). In this context, activities and a learning environment that enable the exploration of ideas and practice of skills without fear of negative repercussions from making mistakes are essential for learning (Alexander, 2008). Through making mistakes, students can become active participants in their learning. For teachers, the art of effective teaching is to capitalize on these mistakes by creating dialogue regarding the errors that result in learning opportunities for students (Schleppenbach, Flevares, Sims, \& Perry, 2007).

There are number of key aspects to creating a learning environment welcoming of mistakes, as suggested in a recent study by Leighton and Gomez (2017). In their research with 101 undergraduate university students Leighton and Gomez found that students felt at ease identifying mistakes and receiving feedback when they had high level of trust in their teacher alongside a learning environment that fostered greater wellbeing. This study compliments the visible learning meta-analysis research by Hattie $(2009,2012)$ which positions positive student teacher relationships, and notions of care, cooperation, trust and respect as key to a learning environment where mistakes are welcomed and learnt from.

A second consideration with respect to students maximising learning from their mistakes is the learner's mindset. Carol Dweck (2006) argues that learners with a growth mindset believe that their abilities can be developed through hard work, hence they are more able to face challenges, more resilient when faced with setbacks, and therefore more likely to learn from mistakes through greater self-awareness and self-esteem. A fixed 
mindset on the other hand, where learners believe their abilities and intelligence are fixed, can lead to avoiding feedback and viewing mistakes as failures rather than situations supportive of further learning. Although participants in this study were not specifically asked about mindsets in relation to mistakes in $\mathrm{OE}$, the work of Dweck demonstrates the importance of creating a learning environment where students can develop abilities to recognise, embrace, and learn from mistakes. How teachers can help students to develop a growth mindset in outdoor education contexts would also be useful future research.

Teachers can make the most of opportunities for error within their pedagogical practice if they maintain the view that mistakes can be used as resources for promoting learning. Mistakes should not be feared by teachers and students, but viewed as tools that lead to higher levels of achievement and deeper levels of comprehension. With respect to mathematics, Kazemi (1998) provided evidence that discussion of mistakes can lead to greater achievement among students. She analysed the work of teachers who practiced "high-press" and "low-press" discourse in their mathematics instruction. High-press teachers invited discussion about student mistakes and created an atmosphere of mutual respect between students where it was safe to err; in contrast, low-press teachers limited discussion of mistakes. Kazemi directly linked high-press teaching to improving student achievement. Within an OE context, this 'high-press' approach could be applied as teachers provide students with lower risk yet challenging learning activities ensuring their physical safety where mistakes with low level consequences are allowed to occur to provide opportunities for feedback, reflection and learning.

The efficacy of learning through mistakes is likely to be compromised if those mistakes are not combined with appropriate feedback. One of the most effective forms of feedback is the notion of rapid formative assessment, or as Wiliam (2011) describes it, assessment that acts as feedback during the learning process. Further to this, Black and Wiliam (2009) provide strategies for teachers to create rapid formative assessment opportunities, which include setting and sharing learning intentions and success criteria, and creating a classroom environment that encourages students to play an active role in their own and each other's learning. When feedback is not simply an end of unit process but a commonplace everyday occurrence, students learn that mistakes and slow progression are not only allowed but also encouraged. Whilst the frequency of feedback from teacher to student must be carefully 
managed to not overwhelm or confuse students (Carless, 2006; Nuthall, 2007), the feedback students can receive from making mistakes is invaluable to the learning process.

It is important to acknowledge that feedback does not only come from teachers; it also comes from other students (peers) and through learner observation, self-reflection and evaluation. A study by Nuthall (2005) found that most of the feedback students received was from peers and that much of that feedback was either incorrect or not helpful in improving performance or mastery of the task. In OE contexts, where students often work together on tasks, it is important to recognise the place of peer feedback while helping students to make sure that the feedback they provide is constructive. At another level, "self-regulation" feedback is important, helping students to seek, accept and deal with feedback, improve confidence and skills in self-evaluation (Hattie, 2012, p.120). Students who can self-monitor and regulate can interpret and apply feedback more effectively.

Philosophies of experiential education emphasize the importance of forms of feedback orientated towards self-evaluation, as highlighted in the work of Itin (1999). Students can gain feedback from the immediate environment or learning context and their reflection on concrete experience. Whilst teachers in this study seldom referred directly to students gathering their own feedback, it is important to keep in mind multiple forms of feedback that may accompany learning from mistakes.

\section{Research Design and Method}

This study sought to better understand how principles of quality teaching and learning, so often associated with classroom-based learning areas, can inform and be applied in OE contexts. The study aims focused on examining the perspectives and experiences of Tasmanian OE teachers relating to the positioning of student mistakes and feedback in the OE teaching and learning process. In order to address the research questions, an interpretive qualitative research approach was adopted. Such a qualitative approach is useful to not only understand the lived experience of outdoor education teachers but to also seek insight into the social practices and structures of their teaching contexts (Silverman, 2016), as these contextual factors are crucial to the way that mistakes are perceived in different learning environments. Semi-structured interviews, which focused on the experiences and perspectives of OE teachers, particularly as they related to the positioning of mistakes within their OE programs and teaching and learning practices, were the primary source of data 
collection. Interview questions were open-ended allowing for participants to create their own options for response in order to share what they believed was important and valuable in relation to this issue (Creswell, 2012). Due to this open-ended nature of questions, there was also a range of prompt questions for the researcher to use to either elicit further detail or clarify responses from participants (Ary, Jacobs \& Sorensen, 2010). All interviews were conducted by one member of the research team.

All interview transcripts were transcribed verbatim and then sent back to participants for member checking to make sure the transcripts were an authentic account of the interviews (O'Leary, 2010). To further enhance the authenticity and trustworthiness of the findings of the study, a systematic analysis process was employed utilising Creswell's (2014) six steps of qualitative data analysis: 1) organising data for analysis, 2) reading through all data, 3) coding the data, 4) looking for related themes and description, 5) deciding on how themes will be presented, and 6) providing interpretation of each theme. Within this analysis process, themes were developed both deductively and inductively. Deductive analysis revealed themes that we thought might occur due to these ideas being prominent in the literature; for example, the relationship between mistakes and feedback. Inductive themes emerged from the data and were less expected; for example, trust and temporal aspects of outdoor education in relation to a learning environment where mistakes are welcomed.

Principles of ethical research were addressed in this study in a variety of ways. Participants provided written informed consent prior to being interviewed; participants were provided with a pseudonym in all data analysis and subsequent writing; participants were provided with a copy of the research dissertation at the completion of the study; and member checking of transcripts was used to ensure an authentic presentation of their perspectives. Participants also had the opportunity to cease their involvement at any stage prior to publication. Prior to commencing this research, the relevant human research and ethics committee at the University of Tasmania approved the project.

The population of participants invited to participate in this research were the 73 members of the Tasmanian Outdoor Education Teachers Association (TOETA) email list. Seven teachers responded and were willing to be interviewed as part of the data collection process. The individual interviews were conducted in June 2014. The seven teachers came from a range of Tasmanian secondary schools and were provided with pseudonyms to protect their identity: Harry, James, Laurence, Kevin, Emily, Max and Helen. It is important 
to acknowledge that OE programs in Tasmanian secondary schools vary in their goals, structure, and learning activities. As such, teachers working within different types of programs had a range of perspectives on dealing with student mistakes depending on their specific goals. Four of the participants (James, Laurence, Max and Emily) identified their OE programs as being compulsory for all students in their school from grade seven to ten. Some of these programs were journey based and some were structured on a range of activities centred around a base camp or outdoor education campus. Two of the participants (Kevin and Helen) worked in senior secondary elective courses offered within the Tasmanian Certificate of Education (TCE). One participant (Harry) offered an elective program as a timetabled subject to year ten students within his school.

\section{Findings and Discussion}

For the purposes of this article we have integrated the findings and discussion for each theme to allow for greater coherence across the data and in-depth interpretation and discussion. Five key themes that emerged from the data analysis are elucidated in the following sections. 1) goals of outdoor education; 2) relationship between mistakes and feedback in the teaching and learning process; 3 ) the relationship between teacher beliefs, mistakes and pedagogical practice; 4) learning environments, trust and time in outdoor education programs; 5) the impact of risk on mistakes and teaching and learning.

\section{The goals of outdoor education programs and the relationship to mistakes: Theme 1}

In order to explore how teachers perceived the role that mistakes played in their outdoor education teaching practice, we thought it important to first understand the goals of their programs. We are mindful of the small number of teachers, and therefore programs, in this study and do not seek to stereotype all OE programs in Tasmania. There were, however, some remarkable similarities. When asked to outline the key goals of their programs, all teachers indicated that their programs were aimed at using the outside environment to create experiential learning opportunities that students could not access within the confines of a traditional classroom. Within that experiential context, six of out seven participants directly referred to notions of personal and inter-personal development. Max and Emily, below, best encapsulated this notion. 
A lot of personal development goals, building self-discipline, concepts of responsibility, being able to push yourself a little bit, what it takes to work well in a team with other people, leadership and teamwork skills (Max).

We have a big focus on personal development and leadership. They are learning new things in what is quite a practical and hands on environment and also working with other people. It can be quite an individual pathway of learning or also one shared with a team. (Emily)

The single exception to this dominant view was Harry who ran a weekly timetabled elective OE subject.

Where we can, we use the local area of the school. I want the students to be confident and independent in the outdoors. I don't focus too much on hard skills, but ... have some initiative to think up the things they want to do and be able to do it. Another part of $\mathrm{OE}$ is for them to understand a bit more about the places we go. Part of that is understanding a little bit about ecology, and learning to appreciate what's there and why it's fragile and why it's not and what inherent values there are in that. (Harry)

Harry's comments reveal broader goals that underpin his program which move beyond challenge activities and personal development. In many ways, Harry's comments reflect shifting discourses occurring in the literature (see for example, Hill, 2012; Hill \& Brown, 2014; Wattchow \& Brown, 2011) which point towards a stronger focus on place, environment and sustainability for OE. One thing that did become apparent was the way that goals related to challenging students and seemed at face value to be commensurate with the idea that students can learn from their mistakes when they are placed in challenging situations, as Laurence suggested. 
If people are sheltered throughout their experience and it is always within a safe umbrella then they cannot learn what it is to be an adult and make mistakes and grow from that. (Laurence)

This relationship between level of challenge, mistakes and learning is further elucidated through the following interview conversation with Emily.

Emily: I feel that when students are learning in an environment where they feel quite challenged, and are outside of their comfort zone, I think that's got a huge influence on the students' learning. That's not necessarily directly linked to making mistakes, however when students do make mistakes I think it leads to them feeling challenged so it ties in with that idea.

Interviewer: So you see challenging activities as leading to a time where mistakes could happen?

Emily: $\quad$ Yeah. After the mistakes are made, great learning comes out of that.

The comments from Laurence and Emily suggest that some teachers see a link between challenge and opportunities for learning from mistakes. Of course it is important to acknowledge here that a mistake, in and of itself, does not always lead to good learning. Rather, student mistakes might be better viewed as a starting point, but not the final destination in the learning process.

The relationship between mistakes and feedback in the teaching and learning process: Theme 2

As identified earlier, the relationship between feedback and mistakes is crucial to the learning process. Participants discussed this notion in different ways during the interviews. From Kevin's perspective, "the mistake is the catalyst, it starts the conversation. It can be the link a student needs that makes one experience more meaningful learning than another." The idea that mistakes are a catalyst to further action that results in learning is important. This point emphasises the significant roles that reflection, evaluation and feedback, and in Kevin's case the "conversation", have in learning from mistakes. Also important is a learning 
environment where mistakes are welcomed and feedback is constructive. Harry expanded on how he places emphasis on this and explains it to his students.

I explain to students that we are going to go and do stuff, but that only becomes meaningful if you think about it ... doing is only part of it, it's really important that you come back and reflect on what occurred, what mistakes were made and what would be done differently in the future. (Harry)

Harry is speaking to the importance of student reflection as part of the process that occurs after a mistake has been made. Prior to stepping in and providing feedback or correcting a mistake, Harry wants the students to realise they have erred and determine their own strategies about why the mistake happened and what they need to do in future to prevent reoccurrences. This process is enhanced when it involves feedback from multiple sources including the teacher, peers, and self-regulation (Hattie, 2012). All participants highlighted the use of student directed discussion and reflections as part of the outdoor learning environment. This emphasises the importance of a discussion surrounding student mistakes and links being made to the learning that needs to occur. It is important to note, however, that whilst all of the OE teachers in this study reflected upon the importance of student-led discussion and storytelling, there are occasions when teacher led feedback can help to better facilitate learning from the mistakes that occurred. Helen provides an example of when this might be appropriate.

Often the students won't understand why things went wrong, so it's really important to ensure there is an understanding of how they got to a certain point in the first place, highlight what went wrong and ask what should have been done to prevent the mistake (Helen).

Helen has provided a distinction between two types of student mistakes, one where it is clear to the students that a mistake has been made, and a second where there is less clarity around the mistake. For both types, Helen commented on the need for students to understand the mistake occurred and for a discussion to occur around it. Participants in this research have clearly represented the view that without some form of feedback the 
presence of mistakes will not lead to student learning or achievement. Helen sums up the relationships between student mistakes and feedback by highlighting that, "with the entire mistake and feedback experience behind them, students may now value what you are teaching more than before any mistakes were made." Helen's statement reinforces the importance of linking feedback to student mistakes to maximise learning. This view seemed to be common across all participants in this study as was the general belief that mistakes are essential in the learning process as reflected below.

\section{The relationship between teacher beliefs, mistakes and pedagogical practice: Theme 3}

Thus far we have identified what seems to be a commonly accepted notion amongst participants, that a vital part of the learning process involves student mistakes accompanied by feedback. James stressed that this "is an essential component of learning within the outdoors ... an absolutely essential part of our program." And while he understood that mistakes accompanied by feedback are an aspect of "learning in general," James acknowledged the importance of this aspect "in an outdoor environment where the outcomes of mistakes are so real and authentic." Helen likewise "fully" agreed "that more learning happens through mistake more than anything else." Emily also concurred, saying that "it is the best type of learning that some can have - that is learning from mistakes."

These comments reflect a common sentiment held by the teachers interviewed that mistakes are indeed a powerful opportunity for learning, as they often occur in what are considered real and authentic ways. How such opportunities for students to learn from mistakes are actually built into OE programs and pedagogical practices is, however, less clear. For instance, James, who commented that student mistakes are an absolutely essential part of his program, offered the following in his interview.

James: We don't deliberately plan our program so that students can make mistakes.

Interviewer: Is there a time in activities where you might encourage students to a point where they might make a mistake?

James: No, I don't think about it in those terms. When I know they are operating within the parameters of their comfort level and are playing 
it safe I simply encourage them to push themselves, but that doesn't necessarily lead to a mistake.

These comments from James may reflect a difficulty in translating the belief that mistakes are essential for learning into practice in an outdoor education context. How are outdoor education programs designed and what are the pedagogical practices employed in those programs that makes learning from mistakes likely to happen? These appear to be difficult questions to answer based on the findings in this study. One answer may lie in the notion of teachable moments, a point that Kevin raised.

Planning for error is impossible to write in to curriculum. I talk a lot about teachable moments ... [where] the outdoor teacher has to have a seat of knowledge and skills that they can recall on as reflex. That allows you to pre-empt some of the things that can occur so you can foresee an error before it occurs and assess whether you are comfortable with that happening or not. (Kevin)

Here Kevin highlights the importance of allowing mistakes to occur through teachable moments. For Kevin, such opportunities are filtered through his own skills, knowledge and experience to assess whether he is comfortable for those mistakes to occur or not. An example might be a student who is about to fill a liquid fuel stove whilst it is still going (clearly not a mistake you are going to let happen), contrasted with an example where students who are inattentive whilst cooking their meal resulting in it potentially burning on the bottom of the pan (a mistake that is more tolerable). Perhaps the notion of teachable moments is a key part to better understanding how teachers can make the most of how learning works by way of mistakes.

According to Blenkinsop, Telford and Morse (2016, p. 352), making the most of "learning moments" is one of the key pedagogical skills that outdoor and experiential educators can use to enhance learning. Crucial to learning moments is the learning environment in which they occur. As Hattie (2012) argues, the creation of an environment where "students feel comfortable about making errors" (p. 71) is a key element of quality teaching and learning and raising student achievement. For teachers in this study, how 
such a learning environment might be developed (or not) seems to be dependent on a number of factors that interact in complex ways, as discussed in the next section.

\section{Learning environments, trust and the temporal nature of outdoor education programs: Theme 4}

When discussing the value of learning from mistakes and the learning environment realities of his programs, James offered the following insight.

There are so many variables that you are contending with in the field that you simply can't plan for mistakes too occur. It's all too risky you know, what is the weather doing, how far away is camp, what needs to happen when we get back to camp, how much of a hurry are we in, do we have enough warm clothes, food, all those sorts of things. So you've always got that operating in the back of your mind as all of this is happening so I don't think there's a clear scenario that you can set up and provide clear parameters around in an environment that is constantly changing. (James)

It is apparent that, from James's perspective, the level of risk and complexity of program impacted on the potential for there to be learning from mistakes. Whilst the implications of risk will be addressed via the next theme, it is useful here to consider how impacts of time and program design contribute to a learning environment that is conducive to learning from mistakes. Findings from OE teachers, such as James, Laurence, Max and Emily, who worked in compulsory, short-term OE programs, generally stated that mistakes were less prominent in their programs and practice. These programs, which were often one week long, centred on students completing a series of outdoor adventure activities in order to develop character traits that James listed as, "resilience, independence, interdependence, integrity, initiative, respect and altruism." Spending more time with students and developing stronger relationships, however, can aid in the creation of a learning environment where student mistakes are welcomed and can be capitalised on educationally, as Helen acknowledged. 
At the start of the trip or first trip with a group I would interfere sooner, but once I know the students and the way they interact I am more comfortable with letting them go and for error to occur. (Helen)

Here Helen revealed that the more she gets to know her students, the more comfortable she is with mistakes being made. As a result of these repetitive interactions with students and the development of teacher-student relationships, the outdoor learning environment is experienced by students as more free from teacher direction, enabling students to make mistakes and benefit from feedback, experiencing valuable learning from this process. This was also the case for Harry who had a yearlong timetabled OE subject with an environmental and sustainability focus. In this context Harry was able to be more deliberate about the role of mistakes in his program.

Harry: I think mistakes are important; they're a fundamental aspect of the experiential learning model.

Interviewer:So how do you plan for them?

Harry: $\quad$ The planning for them is really important, it's the way the teacher maintains total control. This planning involves knowing where you are going, what you are doing and the scope of what you are comfortable with allowing to happen whilst you are there.

This planning allowed Harry to create opportunities where students could make mistakes in his program, but his foresight allowed him to plan how he would react in these situations and appropriately manage levels of risk so that students could still engage with the learning required. Harry actively planned for mistakes to occur. The fact that students were enrolled in a year-long OE course which enabled more long-term development of positive relationships and trust seemed to contribute to the welcoming of mistakes. This highlights Hattie's suggestion that the "optimal classroom climate for learning is one that generates an atmosphere of trust" (2012, p. 26). When examining any learning area, an atmosphere of trust between teacher and student and amongst the students themselves is imperative in the creation of an environment where mistakes are welcome (Killen, 2012). 
This is possible in an OE context, but the findings presented in this research indicate that some OE teachers find this challenging, particularly in short-duration programs.

Yet the mere presence of mistakes does not automatically result in a learning environment that is more conducive to student learning and achievement. Moreover, being welcoming of student mistakes does not necessarily create an abundance of extra mistakes in the learning process. Participants commented that student mistakes are inevitable in all teaching and learning, but how the teacher responds is critical in the activation of student learning. The role of feedback and an open dialogue with respect to mistakes is crucial in the learning process. Due to the nature of some OE programs, however, this feedback process was not always possible. Participants indicated they responded to student mistakes in one of two ways; in higher risk activities where student mistakes are not welcome they are quickly corrected, yet in lower risk situations mistakes can be welcomed, discussed and evaluated.

When discussing error as being a catalyst for effective feedback Hattie (2012) makes the point that "error is the difference between what we know and can do, and what we aim to know and do ... knowing the error is fundamental to moving towards success. That is the purpose of feedback" (p. 115). In this case, the error can be utilised by the teacher as a springboard for inquiry. Feedback, often in the form of reflective questioning, can then be presented to the student so that it decreases the gap between current achievement and where they need to be in order to gain success. In the event where students are unaware a mistake has been made, Killen (2012) suggests feedback can be provided to students so that an awareness is not only created around the specific mistake but also with respect to the creation of self-awareness so that students learn how to learn from mistakes. This process is important to help students develop more autonomy through reflection skills and thus become less reliant on teacher feedback or intervention.

All teachers in this study agreed that mistakes are essential to student learning and achievement in theory. However, within some outdoor learning environments teachers are hesitant to welcome mistakes. Limiting factors on opportunities for learning from student mistakes include the structure of the learning environment, trust, and the temporal nature of programs; however, there is more to it than that. All participants spoke of the $\mathrm{OE}$ environment as being unique in the fact that some mistakes are often more authentic, or real, than those that would occur within a traditional classroom environment. The impact of 
risk on opportunities for student mistakes formed the basis for the second research question as discussed via the next theme.

\section{The impact of risk on learning from mistakes: Theme 5}

As previously mentioned, the level of risk present in certain learning situations can impact dramatically on the way that mistakes are perceived. Participants indicated that the presence of risk in outdoor learning environments often limits opportunities for welcoming student mistakes and the learning that comes with those. Whilst all participants accepted that student mistakes can greatly benefit student learning and achievement, the placement of a risk caveat on all of the discussion around student mistakes within outdoor activities is highlighted by Helen, who argued that "there are simply certain activities where you can't afford for error to happen, so you step in to make sure there are no catastrophic consequences."

For Helen, the presence of risk within certain adventure activities creates an environment where mistakes cannot be welcomed for fear of student injury or other "catastrophic consequences." Risk in this context is often thought of as preventing opportunities for student mistakes. Whilst this was the predominant thought amongst participants, Harry deliberately used a level of manageable and controlled risk to create opportunities for his students that allowed for mistakes and learning to occur as a result. He provided an example of a sea-kayak activity to highlight such learning experiences.

If a student capsizes within the bay, then we are very confident to respond to that and rescue them. If the student capsized beyond that point then it is a lot harder to deal with... It happened a couple of weeks ago actually ... the kids learnt a lot from that experience, when they reflected upon it later that was one of the most significant moments that they had experienced down there and yes, they admitted they had stuffed up when they fell out, but that was ok and through that they learnt so much about why we did all this planning leading up to the activity, why they had learnt about sea kayaking and group management skills that seemed pointless until they saw it in context. That instance where there was 
a mistake, there was a risk that someone would capsize, that eventuated and a whole scenario developed around that which was a much richer learning experience than if everything had have been just fine. (Harry).

In this example, Harry is talking about the activity containing a level of risk that can be managed by the teaching staff. The inclusion of the risk and a tolerance of student mistakes were both worthwhile because of the value added to student learning. Students had undergone a range of planning and skill development activities leading up to this excursion, but according to Harry their learning was much richer because of the fact that they could learn from mistakes. Of course, in order for this learning to occur the mistakes had to take place in a situation where the consequences posed no significant risk to learners or others, i.e., in a low risk or managed environment. This raises an interesting question related to the relationship between risk and mistakes in OE. Are traditional OE activities, which often rely on higher levels of risk, compatible with the sort of learning environment that Hattie (2012) advocates, where mistakes are welcomed? We do not think there is a simple answer to this question but it does invite some examination of the way that outdoor educators view the teaching and learning process and risk.

According to Brown and Fraser (2009), risk has been a central feature within dominant OE discourse and can be seen as "little more than a hammer in its toolbox when it comes to justifying the philosophical position on which much of its practice appears to be based" (p. 61). The hammer metaphor can be interpreted in two ways. Firstly, that risk is often the most used tool to underpin OE experiences; and secondly that sometimes relying just on increased perceived risk as the key driver for learning can be a bit blunt, that is, it does not allow for the nuanced or richer learning that may come through employing alternative educational strategies or philosophies.

Participants spoke about their goals of personal development for students within their pedagogical practice, resulting in challenging students to move beyond their comfort zones. It was clear that participants believed that the presence of risk was a vehicle used to achieve these goals. It is important to note that risk in this context goes just beyond the physical to also include emotional, cognitive and social risks. Over the last decade or so, the role of risk in dominant $\mathrm{OE}$ practice has been critiqued (see for example, Brookes, 2003a, 2003b; Brown, 2010; Brown \& Fraser, 2009; Zink \& Leberman, 2003) and a greater focus has 
been placed on other aspects of quality teaching and learning rather than the central pillar of risky activities. This shift may involve moving away from activities such as abseiling. As Brown and Fraser (2009) explain, due to the high levels of risk associated with potential student mistakes in an abseil, the activity is chosen, planned and controlled by an experienced instructor and the only decision a participant is required to make is whether to go over the edge or not. Brown and Fraser (2009) claim that "little in the way of growth and learning opportunities are afforded in such artificial situations that, in effect, do not require significant decision-making by the learner" (p. 70). Whilst this claim is open to critique by many educators, students, and academics who would readily relay anecdotes of the learning (such as personal confidence) that has come from activities like abseiling, the point we believe Brown and Fraser are making relates to how outdoor education experiences meaningfully engage students with risk and decision making. In the context of this research how risk intertwines with opportunities for students to learn from their mistakes in ways that result in rich and authentic learning, raises interesting questions about how activities and experiences in outdoor education are conceived, designed and facilitated. For some participants in this study, the presence of manageable, controlled risk within activities did lead to authentic learning opportunities for students where mistakes were welcomed. Kevin expands on this further when discussing how the inclusion of risk can create opportunities for student mistakes.

Students need to understand when it is an acceptable time to take a risk. It can be quite good to take a risk as long as you have done the analysis of what the risk is, what the consequences are and how this will affect their decision making. (Kevin)

Kevin's comment reminds us of the importance of carefully considering how risk interacts with, and potentially enhances the learning experience. Creating learning opportunities and environments where students are able to meaningfully self-regulate their own behaviour and determine whether it is safe for them to make mistakes within the current conditions holds much promise for authentic learning. Including risk in this manner might allow the outdoor educator to teach students when it is acceptable to take risks and potentially make mistakes, and when there might be times where behaviour needs to be 
modified to ensure no mistakes occur. Unlike the abseiling example above, the decision was not whether or not to complete an activity, but perhaps based around planning or controlling an activity. The outcomes of the decision would then impact upon the rest of the student group. In this way, students are directing and self-regulating their learning. Brown and Fraser (2009) support using risk in this way to authenticate the learning process where "decisions are socially mediated and consequences for all are considered" (p. 71). This shift in focus in the way risk is conceived and utilised in $\mathrm{OE}$ can allow the $\mathrm{OE}$ teacher to create an environment that is more welcoming of student mistakes. As participants suggested, risk might be better used to teach students about when mistakes are acceptable and to inform their decision making, as opposed to heightening the emotions within an activity or experience.

\section{Conclusion}

Outdoor education philosophy and practice has endured much critical scrutiny in the last two decades. If the field is to take seriously calls such as those from Nicol (2002) and Brown (2009) to engage more broadly with educational theory and research, then more critical and empirical research is needed. This paper has drawn on a small scale qualitative study to discuss the role that mistakes and feedback play in teaching and learning processes. This aim was underpinned by a desire to better understand the perspectives of OE teachers in regard to their pedagogical practice and how they viewed the place of mistakes in enriching student learning.

Participants in this study were clear that mistakes, when accompanied by appropriate feedback, are essential aspects of teaching and learning processes. There was some hesitancy, however, as to how this can be applied in practice, particularly with outdoor education programs that are of short duration, utilise activities where mistakes can have large and negative consequences, and where there are limited opportunities to build a trusting learning environment.

A teacher who did highlight the importance of letting students make mistakes worked with an OE program that was a year-long elective subject for students. Whilst this participant used some activities common in traditional adventure orientated versions of $\mathrm{OE}$, such as sea kayaking, he used risk as a contributing factor to students' decision-making processes and to authenticate the mistakes they may have made. The added time he had available through 
the structure of this program, especially when contrasted with the shorter-term programs of most other participants, meant that this OE teacher, Harry, was able to create relationships with students underpinned by high levels of trust; and with that came a greater acceptance of mistakes in the learning environment. For the teachers involved in this study who were less welcoming of student mistakes, a common theme was the desire to include higher risk activities in week-long programs which were not elective based and hence involved compulsory attendance from a much larger student cohort. This combination of outcome goals and program structures created an environment where learning from mistakes was not always practicable.

We are hesitant to make generalised claims about implications for OE thinking and practice. This study has limitations in that it was small scale and was specific to certain locales and contexts. A larger project with an increased sample size across multiple states in Australia would broaden the range of perspectives and practices considered. A secondary limitation was the inability to attend programs to observe teachers' pedagogy in practice and witness first-hand how both the teacher and students responded to student mistakes. Future research that includes observation and student voice would be beneficial to further develop an understanding of how mistakes are welcomed and used within the learning process in outdoor education.

Notwithstanding the above limitations, we believe that the perspectives of participants in this study can act as a catalyst to encourage outdoor educators to carefully consider the role that mistakes and feedback play in their learning activities and programs. This could involve looking at the duration of programs, reconsidering how risk is conceived and profiled in particular activities, seeking ways to build trusting relationships with students, and designing learning environments where mistakes are welcomed. If we take seriously the claim from Hattie (2012) that "mistakes are the essence of learning" (p. 26), then outdoor educators must more seriously examine how they can maximise student learning through mistakes and feedback. 


\section{REFERENCES}

Alexander, R. (2008). Towards dialogic teaching: Rethinking classroom talk. York, UK: Dialogos.

Ary, D., Jacobs, L., \& Sorensen, C. (2010). Introduction to Research in Education. Belmont, CA: Wadsworth Cengage Learning.

Beames, S. \& Brown, M. (2016). Adventurous learning. London, UK: Routledge.

Berman, D., \& Davis-Berman, J. (2005). Positive psychology and outdoor education. Journal of Experiential Education, 28(1), 17-24.

Black, P. \& Wiliam, D. (2009). Developing the theory of formative assessment. Educational Assessment, Evaluation and Accountability, 21(1), 5-31.

Blenkinsop, S., Telford, J. \& Morse, M. (2016). A surprising discovery: Five pedagogical skills outdoor and experiential educators might offer more mainstream educators in this time of change. Journal of Adventure Education and Outdoor Learning, 16(4), 346-358. DOI:10.1080/14729679.2016.1163272

Brookes, A. (2003a). A critique of neo-Hahnian outdoor education theory. Part two: 'The fundamental attribution error' in contemporary outdoor education discourse. Journal of Adventure Education and Outdoor Learning, 3(2), 119-132. Brookes, A. (2003b). Outdoor education fatalities in Australia 1960-2002. Part 1. Summary of incidents and introduction to fatality analysis. Australian Journal of Outdoor Education, 7 (1), 20-35.

Brookes, A. (2003c). Outdoor education fatalities in Australia 1960-2002. Part 2. Contributing circumstances: Supervision, first aid, and rescue. Australian Journal of Outdoor Education, 7(2), 34-42.

Brookes, A. (2004). Outdoor education fatalities in Australia 1960-2002. Part 3. Environmental circumstances. Australian Journal of Outdoor Education, 8(1), 44-56.

Brown, M. (2008). Comfort zone: Model or metaphor? Australian Journal of Outdoor Education, 12(1), 3-12.

Brown, M. (2009). Reconceptualising outdoor adventure education: Activity in search of an appropriate theory. Australian Journal of Outdoor Education, 13(2), 3-13.

Brown, M. (2010). Transfer: Outdoor adventure education's Achilles heel? Changing participation as a viable option. Australian Journal of Outdoor Education, 14(1), 
13-22.

Brown, M. \& Fraser, D. (2009). Re-evaluating risk and exploring educational alternatives. Journal of Adventure Education and Outdoor Learning, 9(1), 61-77.

Carless, D. (2006). Differing perceptions in the feedback process. Studies in Higher Education, 31(2), 219-233.

Creswell, J. (2012). Educational research: Planning, conducting, and evaluating quantitative and qualitative research. Boston, MA: Pearson.

Creswell, J. (2014). Research design: Qualitative, quantitative, and mixed methods approaches (4th ed.). Thousand Oaks, CA: Sage.

Dweck, C. S. (2006). Mindset: The new psychology of success. New York, NY: Random House.

Earl, L. M. (2013) Assessment as learning: Using classroom assessment to maximise student learning ( $2^{\text {nd }}$ ed.). Thousand Oaks, CA: Corwin.

Ewert, A. (1983). Outdoor adventure and self-concept: A research analyses. Eugene, OR: University of Oregon.

Hahn, K. (1957). Outward bound. New York, NY: World Books.

Hattie, J., Marsh, H., Neill, J., \& Richards, G. (1997). Adventure education and Outward Bound: Out-of-class experiences that make a lasting difference. Review of Educational Research, 67(1), 43-87.

Hattie, J. (2009). Visible learning: A synthesis of meta-analyses relating to achievement. London, UK: Routledge.

Hattie, J. (2012). Visible learning for teachers: Maximising impact on learning. Oxon, UK: Routledge.

Higgins, R., Hartley, P., \& Skelton, A. (2001). Getting the message across: The problem of communicating assessment feedback. Teaching in Higher Education, 6(2), 269-274.

Hill, A. (2010). Reflections on beliefs and practices from New Zealand outdoor educators: Consistencies and conflicts. Australian Journal of Outdoor Education, 14(1), 30-40.

Hill, A. (2012). Developing approaches to outdoor education that promote sustainability education. Australian Journal of Outdoor Education, 16(1), 15-27.

Hill, A., \& Brown, M. (2014). Intersections between place, sustainability and 
transformative outdoor experiences. Journal of Adventure Education \& Outdoor Learning, 14(3), 217-232.

Hunt, J. S., Jr. (1990). Ethical issues in experiential education. Boulder, CO: The Association for Experiential Education.

Itin, C. M. (1999). Reasserting the philosophy of experiential education as a vehicle for change in the 21st century. Journal of Experiential Education 22(2), 91-98.

Kazemi, E. (1998). Discourse that promotes conceptual understanding. Teaching Children Mathematics, 4(7), 410-414.

Killen, R. (2012). Effective teaching strategies: Lessons from research and practice. South Melbourne, VIC: Cengage Learning Australia.

Leberman, S., \& Martin, A. (2003). Does pushing comfort zones produce peak learning experiences? Australian Journal of Outdoor Education, 7(1), 10-19.

Leighton, J. P. \& Gomez, M. C. B. (2017). A pedagogical alliance for trust, wellbeing and the identification of errors for learning and formative assessment. Educational Psychology, 1-26. DOI:10.1080/01443410.2017.1390073.

Luckner, L., \& Nadler, R. (1997). Processing the experience: Strategies to enhance and generalize learning. Dubuque, IA: Kendall Hunt.

Lugg, A. (2004). Outdoor adventure in Australian outdoor education: Is it a case of roast for Christmas dinner? Australian Journal of Outdoor Education, 8(1), 4-11.

Martin, P. (2008). Outdoor education in senior schooling: Clarifying the body of knowledge. Australian Journal of Outdoor Education, 12(1), 13.

Nicol, R. (2002). Outdoor education: Research topic or universal value. Journal of Adventure Education and Outdoor Learning, 2(2), 85-99.

Nuthall, G. (2005). The cultural myths and realities of classroom teaching and learning: A personal Journey. Teachers College Record, 107(5), 895-934.

Nuthall, G. (2007). The hidden lives of learners. Wellington, NZ: New Zealand Council for Educational Research.

O'Leary, Z. (2010). The essential guide to doing your research project. London, UK: Sage Publications. 
Payne, P., \& Wattchow, B. (2008). Slow pedagogy and placing education in posttraditional outdoor education. Australian Journal of Outdoor Education, 12(1), 25-38.

Purkey, W. (1992). An introduction to invitational theory. Journal of Invitational Theory and Practice, 1(1), 5-15.

Sadler, D. R. (1989). Formative assessment and the design of instructional systems. Instructional Science, 18(2), 119-144.

Schleppenbach, M., Flevares, L., \& Sims, L. (2007). Teachers' responses to student mistakes in Chinese and US mathematics classrooms. The Elementary School Journal, 108(2), 131-137.

Siegel, M. \& Carey, R. (1989). Critical thinking: A semiotic perspective. Bloomington, IN: ERIC Clearinghouse on Reading and Communication Skills.

Silverman, D. (2016). Introducing qualitative research. In D. Silverman (Ed.), Qualitative Research (4th ed., pp. 3-14). Thousand Oaks, CA: Sage.

Stoll, L., Fink, D., \& Earl, L. (2003). It's about learning (and it's about time). London, UK: RoutledgeFalmer.

Wattchow, B., \& Brown, M. (2011). A pedagogy of place: Outdoor education for a changing world. Clayton, VIC: Monash University Publishing.

Wiliam, D. (2011). Embedded formative assessment. Bloomington, IN: Solution Tree Press.

Zink, R., \& Leberman, S. (2003). Risking a debate - redefining risk and risk management. A New Zealand study. New Zealand Journal of Outdoor Education: Ko Tane Mahuta Pupuke, 1(2), 63-76. 